\title{
Current perspectives on the spread of dengue in India
}

\author{
This article was published in the following Dove Press journal: \\ Infection and Drug Resistance \\ II December 2014 \\ Number of times this article has been viewed
}

\author{
Ekta Gupta \\ Neha Ballani \\ Department of Clinical Virology, \\ Institute of Liver and Biliary Sciences, \\ New Delhi, India
}

Correspondence: Ekta Gupta Department of Clinical Virology, Institute of Liver and Biliary Sciences, New Delhi, India

Email ektagaurisha@gmail.com

\begin{abstract}
Dengue fever (DF) and dengue hemorrhagic fever (DHF) are important arthropodborne viral diseases. Each year, there are $\sim 50$ million dengue infections and $\sim 500,000$ individuals are hospitalized with DHF, mainly in Southeast Asia. Dengue in India has dramatically expanded over the last few decades, with rapidly changing epidemiology. The first major DHF outbreak in the entire nation occurred in 1996 by dengue virus serotype 2, and after a gap of almost a decade, the country faced yet another DF outbreak in the year 2003 by dengue virus serotype 3. A dramatic increase in the number and frequency of outbreaks followed, and, at present, in most of the states of India, dengue is almost endemic. At present, all the four serotypes are seen in circulation, but the predominant serotype keeps changing. Despite this trend, surveillance, reporting, and diagnosis of dengue remain largely passive in India. More active community-based epidemiological studies with intensive vector control and initiatives for dengue vaccine development should be geared up to control the spread of dengue in India. We review here the factors that may have contributed to the changing epidemiology of dengue in India.
\end{abstract}

Keywords: dengue, epidemiology, India, pathogenesis, vaccine

\section{Introduction}

Dengue virus infection is a major, growing public health problem with an estimated 2.5 billion people at risk of infection. Dengue viruses can cause a wide variety of clinical illnesses ranging from mildly symptomatic dengue fever (DF) to more dangerous clinical conditions with capillary leakage syndrome such as dengue shock syndrome (DSS) and dengue hemorrhagic fever (DHF). ${ }^{1}$ Globally, dengue virus transmission has expanded in recent years, and all four dengue virus serotypes are now circulating in Asia, Africa, and the Americas. ${ }^{1}$

Dengue in India has dramatically expanded over the last few decades, with rapidly changing epidemiology. ${ }^{2-4}$ Although the first mention of occurrence of dengue in India is said to be in 1780, the first confirmed outbreak occurred in Kolkata in 1963-1964. ${ }^{5-7}$ It took almost 30 years for dengue to eventually spread throughout the entire country, resulting in the first major nationwide outbreak of DHF in the year $1996 .{ }^{8-11}$ Following this, gradual dengue virus expansion started in the entire nation, and northern parts of India faced yet another outbreak in 2003. ${ }^{12,13}$ A dramatic increase in the number and frequency of outbreaks followed, and, at present, in most of the states of India, all four serotypes are prevalent. ${ }^{2,4,14}$ This paper, therefore, reviews current perspectives of the spread of dengue in India and its implications. 


\section{Dengue virus}

Dengue virus belongs to the genus Flavivirus in the family Flaviviridae. It is a positive-stranded encapsulated ribonucleic acid (RNA) virus that is composed of three structural protein genes that encode the nucleocapsid or core protein, a membrane-associated protein, an enveloped glycoprotein, and seven nonstructural proteins. It is transmitted mainly by the Aedes aegypti mosquito and also by the Aedes albopictus mosquito. There are four antigenetically related but distinct serotypes of the dengue virus: DENV-1, DENV-2, DENV-3, and DENV-4. Each serotype has several subtypes or genotypes. DENV-1 has three, DENV-2 has two, and DENV-3 and DENV-4 each have four. In humans, one serotype produces lifelong immunity against reinfection but only temporary and partial immunity against the other serotypes. ${ }^{15}$ Each serotype has unique characteristics and can present with severe manifestations in a particular population depending upon its interaction with the host response.

\section{Changing epidemiology in India}

The Indian encounter with dengue is interesting and intriguing. The epidemiology of dengue in India is very complex and ever changing. Though the first reported occurrence of dengue fever in India was in 1946, there were no major outbreaks in the country for almost 20 years, until a major epidemic occurred in 1963-1964 in Kolkata. ${ }^{16-18}$ It gradually spread to involve North India in 1967-1968 and also South India. ${ }^{19,20}$ All four serotypes of the virus were reported from South India. ${ }^{21}$ Again, after almost three decades of very low incidence, the first major outbreak of DF/DHF occurred in Delhi in 1996 where 10,252 cases and 423 deaths were reported. ${ }^{10}$ This outbreak was caused by DENV-2, genotype IV strain of the virus. ${ }^{22}$ Similar strains of the DENV-2 were reported from central India (Gwalior) and southern India, indicating that the predominant circulating strain in India that time was DENV-2. ${ }^{23}$ In the post-epidemic period in Delhi in 1997, DENV-1 was also seen in circulation. ${ }^{24}$

Dengue started spreading in the interior of India with reported cases from western and southern India. Awareness of this disease and diagnostic modalities also grew, and more frequent reporting of cases occurred. In northern parts of India, the number of reported DF/DHF cases increased, probably because, as now, the health authorities of the country became more vigilant, and timely reporting of all cases was initiated. Serotypes of the virus kept changing from year to year, and each time that either the serotype showed a change or the genotype showed a change, increased cases were seen in that area. ${ }^{13}$ By $1996-2003$, almost all the four serotypes were reported, and frequency of the outbreaks also increased in the population (Table 1). ${ }^{25-33}$

In 2003, another major outbreak engulfed northern and central India (particularly in Delhi and Gwalior), and at this time, all four serotypes were seen in circulation for the first time in Delhi., ${ }^{214}$ The major serotype reported both from Delhi and Gwalior was DENV- 3.,13 The reemergence of this epidemic strain of DENV-3 in Delhi in 2003 and its persistence in subsequent years marked a changing trend in DENV circulation in India. This again showed the shift in the epidemiology of dengue virus in India. Subsequently, recurring outbreaks of DF/DHF were reported in the years 2005-2008 from various states in India, namely Andhra Pradesh, Delhi, Goa, Haryana, Gujarat, Karnataka, Kerala, Maharashtra, Rajasthan, Uttar Pradesh, Pondicherry, Punjab, Tamil Nadu, West Bengal, and Chandigarh. ${ }^{34}$ India reported a total of 28,292 cases and 110 deaths in 2010 , the highest number of cases and number deaths in a single year in the country in the previous two decades. In Delhi, following predominance of the DENV-3 strain from 2003-2006, DENV-1 circulation was seen. ${ }^{32} \mathrm{~A}$ shift in the age group involvement from children to young adults was also noticed in several studies from India. ${ }^{2,12}$ Concurrent infection with multiple serotypes of dengue was also seen. ${ }^{35,36}$ Thus, it is evident that now in India there is a definite increase in the frequency and number of outbreaks along with co-circulation of all four serotypes, hinting toward hyperendemicity of dengue in India.

\section{Burden of disease in India}

According to the World Health Organization, the incidence of dengue globally has shot up 30 -fold in the past 50 years. The cumulative dengue diseases burden has attained an unprecedented proportion in recent times with a sharp

Table I Yearly prevalence of various dengue serotypes in India

\begin{tabular}{|c|c|c|c|}
\hline Year & State & $\begin{array}{l}\text { Prevalent } \\
\text { serotype }\end{array}$ & Reference \\
\hline 1964 & Tamil Nadu & 2 & Myers et $\mathrm{al}^{25}$ \\
\hline 1968 & Tamil Nadu & $\mathrm{I}, 2,3$, and 4 & Myers et $\mathrm{al}^{26}$ \\
\hline 1970 & Uttar Pradesh & $\mathrm{I}, 2,3$, and 4 & Chaturvedi et $\mathrm{al}^{27}$ \\
\hline 1996 & Uttar Pradesh & 2 & Agarwal et al'I \\
\hline 1996 & Delhi & 2 & Aggarwal et al ${ }^{9}$ \\
\hline 1996 & Haryana & 3 & Kumar et $\mathrm{al}^{28}$ \\
\hline 1997 & Delhi & I & Vajpayee et $\mathrm{al}^{24}$ \\
\hline 2001 & Madhya Pradesh & 2 & Parida et $\mathrm{al}^{29}$ \\
\hline $2003-2005$ & Delhi & $\mathrm{I}, 2,3$, and 4 & Gupta et $\mathrm{al}^{2}$ \\
\hline $2007-2009$ & Delhi & $\mathrm{I}, 2,3$, and 4 & Matlani et $\mathrm{al}^{30}$ \\
\hline $2009-2010$ & Maharashtra & 4 & Dayaraj et $\mathrm{al}^{3 \mathrm{l}}$ \\
\hline $2010-2011$ & Delhi & I & Gupta et $\mathrm{al}^{32}$ \\
\hline $2009-2012$ & Uttar Pradesh & I, 2, and 3 & Mishra et $\mathrm{al}^{33}$ \\
\hline
\end{tabular}


increase in the size of human population at risk. Dengue disease presents highly complex pathophysiological, economic, and ecologic problems. ${ }^{37}$ One billion people (15\% of the world's population) reside in India. India's population is twice that of Southeast Asia, the region that currently reports the most dengue-related deaths. A recent study done at the University of Oxford using a map-based approach to model how many dengue cases were occurring in various parts of the world, estimated that India had the largest number of dengue cases, with about 33 million apparent and another 100 million asymptomatic infections occurring annually. ${ }^{38}$

Quantifying the burden of dengue is critical for policy makers to set policy priorities and make informed decisions about disease control. Surveillance for dengue has been very limited in India, and reporting to the central government has also not been mandatory. In 2004, a World Health Organization initiative called for promoting improvement of dengue surveillance as part of the Integrated Disease Surveillance Programme in India, strengthening laboratory networking and quality assurance, and reviewing case definitions. ${ }^{39}$ Although improvements are being made, the current gaps in epidemiological data and surveillance mean that the burden of dengue in India probably is much higher.

\section{Pathogenesis of dengue}

Replication of the dengue virus occurs within mononuclear cells including skin dendritic cells, tissue macrophages, peripheral blood monocytes, and hepatocytes. At present, the host cell receptors involved in the viral entry are mostly unknown. ${ }^{40}$ Primary or first infection in nonimmune persons usually causes DF. Subsequent dengue infection by a different serotype causes more severe illness, such as DHF/ DSS. The key manifestations of DHF/DSS are sudden onset of shock, capillary leakage, and hemorrhagic diathesis/ thrombocytopenia occurring at the time of defervescence of fever. Pathogenesis is not well-defined, but it is suggested that during secondary infection with a different serotype, cross-reactive nonneutralizing antibodies bind to DENV and facilitate uptake via Fc receptors, resulting in enhanced viral replication. The resultant higher viral antigen load leads to an exaggerated activation of cross-reactive dengue specific $\mathrm{T}$ cells. Biological mediators released by the activated $\mathrm{T}$ cells as well as virus-infected cells along with complement activation by viral proteins and immune complexes are implicated in increasing vascular permeability and coagulopathy. ${ }^{41}$ This phenomenon is known as antibodydependent enhancement.

\section{Dengue case definition}

Earlier guidelines classified dengue into three categories: DF, an acute febrile illness; DHF (grades 1 and 2), a syndrome characterized by increased vascular permeability; and altered hemostasis that may progress to hypovolemic shock known as DSS (grades 3 and 4). ${ }^{42}$ The new revised clinical classification of dengue cases now divides the clinical cases into two categories: dengue with or without warning signs, and severe dengue infection (Figure 1)..$^{43}$

\section{Diagnosis of dengue virus infection}

Laboratory diagnosis of dengue is routinely done by demonstration of antidengue immunoglobulin $\mathrm{M}(\operatorname{IgM})$ antibodies or by nonstructural protein 1(NS-1) antigen in patients' serum/plasma depending upon day of illness using either enzyme-linked immunosorbent assay (ELISA) or immune chromatographic-based rapid card tests (Figure 2). Rising titer of dengue immunoglobulin $\mathrm{G}$ ( $\mathrm{IgG}$ ) antibody can also be used for the diagnosis. Virus isolation techniques are very specific but rarely used due to increased complexity and the time taken to obtain results. The Aedes albopictus (A. albopictus) mosquito C6/36 cell line is the method of choice for virus isolation, although other mosquito and mammalian cell lines (such as Aedes pseudoscutellaris, Vero and LLC-MK2 cells) can also be used. Molecular methods such as reverse transcriptase polymerase chain reaction (RT-PCR) or real time polymerase chain reaction (qRT-PCR) are being increasingly used in diagnosis. A single tube nested PCR with primers directed against serotype specific regions of the viral is routinely used for typing of the virus. ${ }^{44}$

\section{Treatment of dengue virus infection}

Currently, no effective antiviral agents to treat dengue infection are available. The management of dengue virus infection is essentially supportive and symptomatic. Intravenous rehydration is the therapy of choice; this intervention can reduce the case fatality rate to less than $1 \%$ of severe cases. The dynamic nature of dengue demands close monitoring and repeated clinical and laboratory evaluations. A rapid response to platelet and fresh frozen plasma and cryoprecipitate transfusion is seen. ${ }^{45}$

\section{Prevention of dengue Vector control}

With limited therapeutic strategies and the current lack of a vaccine, effective vector control methods are an essential component to reduce dengue-related mortality and morbidity. A. aegypti is the most common vector of dengue in India, 


\section{Dengue case classification}

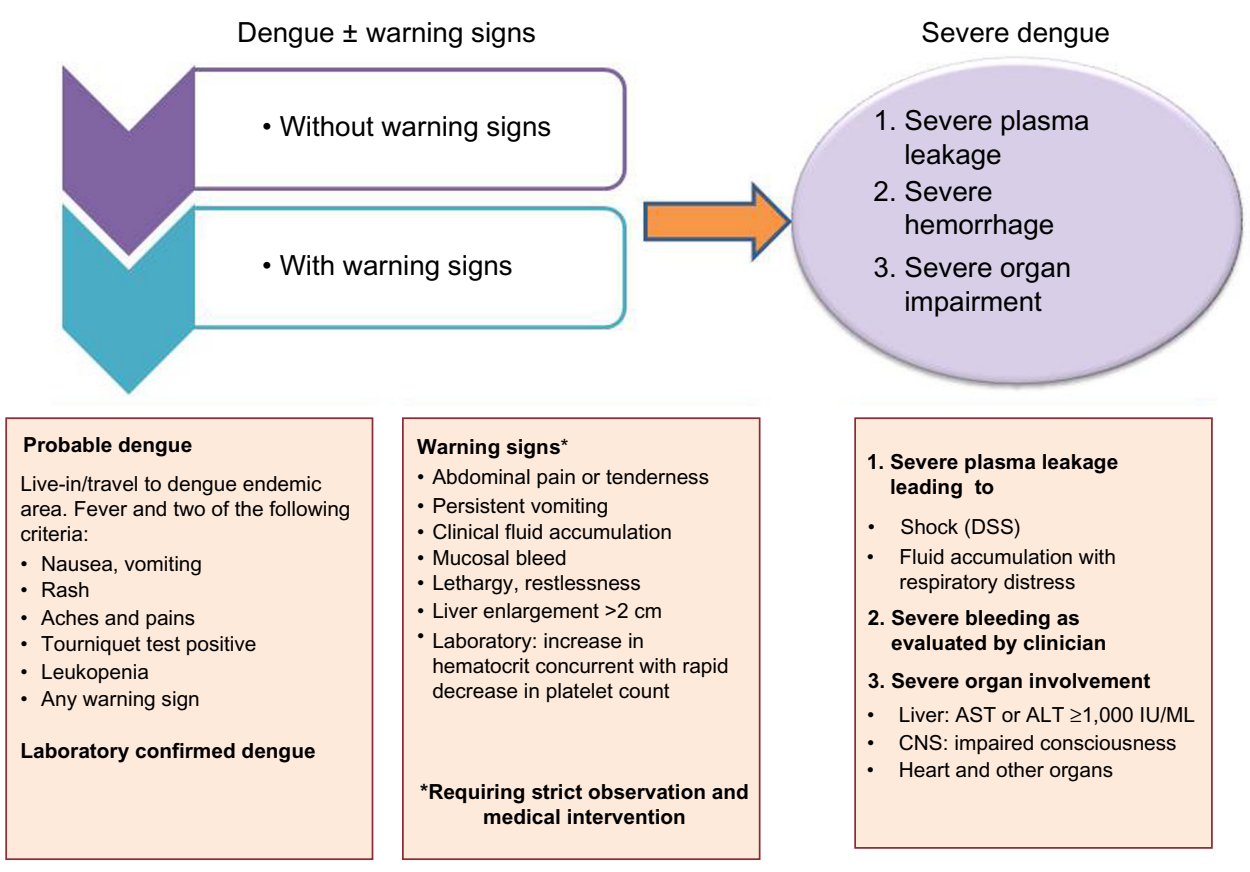

Figure I Dengue case classification by severity.

Abbreviations: DSS, dengue shock syndrome; AST, aspartate aminotransferase; ALT, alanine aminotransferase; CNS, central nervous system; IU, international units; ml, millilitre.

followed by $A$. albopictus. Water-holding containers, eg, plastic, metal drums, and cement tanks facilitate breeding of Ae. aegypti. Vector control methods involve environmental, chemical, and biological management approaches. Utilizing an effective integrated vector control strategy with a combination of approaches, such as social mobilization and integration of chemical and nonchemical vector control methods targeting areas of high human-vector contact, will aid in reducing dengue transmission. The evolution and spread of resistance to insecticides is a growing concern for

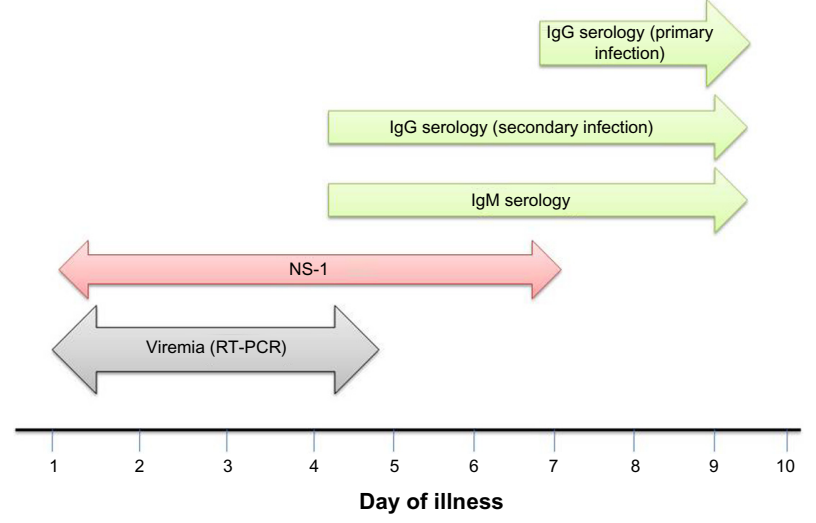

Figure 2 Laboratory diagnosis of dengue.

Note: Day 0 is the first day when the patient noted any symptom during this illness. Abbreviations: IgG, immunoglobulin G; IgM, immunoglobulin M; NS- I, nonstructural protein I; ELISA, enzyme-linked immunosorbent assay; RT-PCR, reverse transcriptase polymerase chain reaction. the control of dengue vectors. Bioassay data demonstrate that resistance to organophosphates (temephos) and pyrethroids is widespread in $A$. aegypti, and resistance has also been reported in A. albopictus. ${ }^{46}$ Monitoring resistance is, therefore, necessary to ensure that effective insecticides are being used. The National Vector Borne Disease Control Program has been initiated to control the emerging threat by vectorborne diseases in India. Despite extensive efforts in developing the effective dengue control measures, several factors pose difficulties in implementing efficient vector control measures, such as large population size, lack of awareness, lack of education, and poverty.

\section{Integrated surveillance}

Surveillance is an essential component of any dengue prevention and control program, as it provides the necessary information for risk assessment and program guidance. Surveillance utilizes both passive and active data collection methodologies. Laboratory support is a critical component in any kind of surveillance. ${ }^{47,48}$ The laboratory should be able to identify not only the presence of the dengue virus but also its serotype and to correlate these to the severity of illness and whether the patients are experiencing a primary or secondary dengue infection. Furthermore, information on the genetic sequence of the circulating viruses, both during and between dengue epidemics, would be of great value to 
predict epidemics. In India, the government's initiative ${ }^{49}$ to set up virology diagnostic laboratories in different states along with initiation of a national program has geared up the surveillance activities; however, a lot more remains to be achieved for effective surveillance.

\section{Toward a new vaccine}

To date, an effective vaccine to protect against dengue is lacking owing to several challenges such as the requirement of a tetravalent vaccine providing long-term homotypic and heterotypic protection, the lack of an adequate animal disease model, and the resulting uncertainty around correlates of protection. However, several candidate vaccines are in various phases of trials. The ideal dengue vaccine should be free of important reactogenicity, induce life-long protection against infection with any of the four DENV serotypes, and be affordable. The candidate currently at the most advanced clinical development stage, a live-attenuated tetravalent vaccine based on the chimeric yellow fever-dengue virus, has progressed to phase III efficacy studies. ${ }^{50}$ The safety and clinical efficacy of the chimeric yellow fever-dengue virus have so far shown promising results. ${ }^{51}$ Several other vaccine candidates like live-attenuated, subunit, deoxyribonucleic acid(DNA) and purified inactivated vaccines, are at earlier stages of clinical development. Additional technological approaches, such as virus-vectored and virus-like particle-based vaccines, are under evaluation in preclinical studies.

\section{Conclusion}

Dengue in India has established its roots. Now it is endemic and almost hyperendemic in our population. National level comprehensive studies to estimate the true burden of dengue in India and its geographical mapping are lacking. Through integrated and combined efforts from various sectors and policy makers, prevention of dengue must be intensified to control further disease transmission.

\section{Disclosure}

The authors report no conflicts of interest in this work.

\section{References}

1. Gubler DJ. The changing epidemiology of yellow fever and dengue, 1900 to 2003: full circle? Comp Immunol Microbiol Infect Dis. 2004;27: 319-330.

2. Gupta E, Dar L, Kapoor G, Broor S. The changing epidemiology of dengue in Delhi, India. Virol J. 2006;3:92-96.

3. Gupta N, Srivastava S, Jain A, Chaturvedi UC. Dengue in India. Indian J of Med Res. 2012;136:373-390.

4. Chakravarti A, Matlani M, Kashyap B, Kumar A. Awareness of changing trends in epidemiology of dengue fever is essential for epidemiological surveillance. Indian J Med Res. 2012;30:222-226.
5. Chaturvedi UC, Nagar R. Dengue and dengue haemorrhagic fever: Indian perspective. J Biosci. 2008;33:429-441.

6. Sarkar JK, Chatterjee SN, Chakravarty SK. Haemorrhagic fever in Calcutta: some epidemiological observations. Indian J Med Res. 1964;52:651-659.

7. Chatterjee SN, Chakravarti SK, Mitra AC, Sarkar JK. Virological investigation of cases with neurological complications during the outbreak of haemorrhagic fever in Calcutta. J Indian Med Assoc. 1965;45:314-316.

8. Prabhakar H, Mathew P, Marshalla R, Arya M. Dengue haemorrhagic fever outbreak in October-November 1996 in Ludhiana, Punjab, India. Indian J Med Res. 1997;106:1-3.

9. Aggarwal A, Chandra J, Aneja S, Patwari AK, Dutta AK. An epidemic of dengue hemorrhagic fever and dengue shock syndrome in children in Delhi. Indian Pediatr. 1998;35:727-732.

10. Dar L, Broor S, Sengupta S, Xess I, Seth P. The first major outbreak of dengue hemorrhagic fever in Delhi, India. Emerg Infect Dis. 1999;5:589-590.

11. Agarwal R, Kapoor S, Nagar R, et al. A clinical study of the patients with dengue hemorrhagic fever during the epidemic of 1996 at Lucknow, India. Southeast Asian J Trop Med Public Health. 1999;30:735-740.

12. Gupta E, Dar L, Narang P, Srivastava VK, Broor S. Serodiagnosis of dengue during outbreak at a tertiary care hospital in Delhi. Indian $J$ Med Res. 2005;121:36-38.

13. Dash PK, Saxena P, Abhyankar A, Bhargava R, Jana AM. Emergence of dengue virus type-3 in northern India. Southeast Asian J Trop Med Public Health. 2005;36:370-377.

14. Dar L, Gupta E, Narang P, Broor S. Cocirculation of dengue serotypes, Delhi, India, 2003. Emerg Infect Dis. 2006;12:352-353.

15. Wahala WM, Silva AM. The human antibody response to dengue virus infection. Viruses. 2011;3:2374-2395.

16. Karamchandani PV. Dengue group of fevers in India. Lancet. 1946;1(6386):92.

17. Ramakrishanan SP, Gelfand HM, Bose PN, Sehgal PN, Mukharjee RN. The epidemic of acute haemorrhagic fever, Calcutta: epidemiological inquiry. Indian J Med Res. 1964;52:633-650.

18. Sarkar JK, Pavri KM, Chatterjee SN, Chakravarty SK, Anderson CR. Virological and serological studies of cases of haemorrhagic fever in Calcutta. Indian J Med Res. 1964;52:684-691.

19. Balaya S, Paul SD, D'Lima LV, Pavri KM. Investigations on an outbreak of dengue in Delhi in 1967. Indian J Med Res. 1969;57:767-774.

20. Ghosh BN. A study on the epidemic of dengue-like fever in Pondicherry (1964-65 and 1965-66). J Indian Med Assoc. 1968;51:261-264.

21. Myers RM, Varkey MJ, Reuben R, Jesudass ES. Dengue outbreak in Vellore, southern India, in 1968, with isolation of four dengue types from man and mosquitoes. Indian J Med Res. 1970;58:24-30.

22. Singh UB, Maitra A, Broor S, Rai A, Pasha ST, Seth P. Partial nucleotide sequencing and molecular evolution of epidemic causing dengue 2 strains. J Infect Dis. 1999;180:959-965.

23. Dash PK, Parida MM, Saxena P, et al. Emergence and continued circulation of dengue-2 (genotype IV) virus strains in northern India. J Med Virol. 2004;74:314-322.

24. Vajpayee M, Mohankumar K, Wali JP, Dar L, Seth P, Broor S. Dengue virus infection during post-epidemic period in Delhi, India. Southeast Asian J Trop Med Public Health. 1999;30:507-510.

25. Myers RM, Carey DE. Concurrent isolation from patient of two arboviruses, Chikungunya and dengue type 2. Science. 1967;157: 1307-1308.

26. Myers RM, Varkey MJ, Reuben R, Jesudass ES. Dengue. outbreak in Vellore, southern India, in 1968, with isolation of four dengue types from man and mosquitoes. Indian J Med Res. 1970;58:24-30.

27. Chaturvedi UC, Mathur A, Mehrotra RM. Experimentally produced cardiac injury following dengue virus infection. Indian J Pathol Bacteriol. 1974; 17:218-220.

28. Kumar A. Sharma SK, Padbidri VS, Thakare JP, Jain DC, Datta KK. An outbreak of dengue fever in rural areas of northern India. J Commun Dis. 2001;33:274-281.

29. Parida MM, Dash PK, Upadhyay C, Saxena P, Jana AM. Serological and virological investigation of an outbreak of dengue fever in Gwalior, India. Indian J Med Res. 2002;116:248-254. 
30. Matlani M, Chakravarti A. Changing trends of dengue disease: a brief report from a tertiary care hospital in New Delhi. Braz J Infect Dis. 2011;15:184-185.

31. Dayaraj C, Kakade MB, Bhagat AB, et al. Detection of dengue-4 virus in Pune, western India after an absence of 30 years - its association with two severe cases. Virol J. 2011;8:46-49.

32. Gupta E, Mohan S, Bajpai M, Choudhary A, Singh G. Circulation of Dengue virus-1 (DENV-1) serotype in Delhi, during 2010-11 after Dengue virus-3 (DENV-3) predominance: a single centre hospital-based study. J Vector Borne Dis. 2012;49:82-85.

33. Mishra G, Jain A, Prakash O, et al. Molecular characterization of dengue viruses circulating during 2009-2012 in Uttar Pradesh, India. J Med Virol. Epub June 2, 2014.

34. Dash AP, Bhatia R, Kalra NL. Dengue in South-East Asia: an appraisal of case management and vector control. In: World Health Organization, Dengue Bulletin, volume 36. Geneva: World Health Organization; 2012: 1-13. Available from: http://www.wpro.who.int/mvp/ epidemiology/dengue/Dengue_Bulletin_Vol36.pdf. Accessed August 29, 2014.

35. Bharaj P, Chahar HS, Pandey A, et al. Concurrent infections by all four dengue virus serotypes during an outbreak of dengue in 2006 in Delhi, India. Virol J. 2008;5:1.

36. Gupta E, Dar L, Broor S. Concurrent infection by two dengue virus serotypes among dengue patients. Indian J Med Microbiol. 2008;26: $402-403$.

37. Gubler DJ. The economic burden of dengue. Am J Trop Med Hyg. 2012;86:743-744

38. Bhatt S, Gething PW, Brady OJ, et al. The global distribution and burden of dengue. Nature. 2013;496:504-507.

39. Integrated Disease Surveillance Project (IDSP) Training Manual for Medical Officers for Hospital Based Disease Surveillance National Centre for Disease Control (NCDC). http://idsp.nic.in/idsp/IDSP/ MedOff.pdf. Accessed on 29.08.14.

40. Jessie K, Fong MY, Devi S, Lam SK, Wong KT. Localization of dengue virus in naturally infected human tissues, by immunohistochemistry and in situ hybridization. J Infect Dis. 2004;189:1411-1418.

41. Halstead SB. Antibody, macrophages, dengue virus infection, shock, and hemorrhage: a pathogenetic cascade. Rev Infect Dis. 1989;11(Suppl 4): S830-S839.
42. World Health Organization. Clinical diagnosis. In: Dengue Haemorrhagic Fever: Diagnosis, Treatment, Prevention and Control. 2nd ed. Geneva: World Health Organization; 1997:12-33. Available from: http://www.who.int/csr/resources/publications/dengue/012-23. pdf. Accessed August 29, 2014.

43. World Health Organization and the Special Programme for Research and Training in Tropical Diseases. Dengue: Guidelines for Diagnosis, Treatment, Prevention and Control. New edition. Geneva: World Health Organization; 2009. Available from: http:/www.who.int/tdr/publications/documents/dengue-diagnosis.pdf. Accessed August 29, 2014.

44. Lanciotti RS, Calisher CH, Gubler DJ, Chang GJ, Vorndam AV. Rapid detection and typing of dengue viruses from clinical samples by using reverse transcriptase-polymerase chain reaction. J Clin Microbiol. 1992;30:545-551.

45. Chaudhary R, Khetan D, Sinha S, et al. Transfusion support to Dengue patients in a hospital based blood transfusion service in north India. Transfus Apher Sci. 2006;35:239-244.

46. Ranson H, Burhani J, Lumjuan N, Black WC IV. Insecticide resistance in dengue vectors. TropIKA Reviews. 2010;1:1. Available from: http://journal.tropika.net/scielo.php?script=sci_arttext\&pid=s207886062010000100003\&lng=en. Accessed August 29, 2014.

47. Rigau-Perez JG, Gubler DJ. Surveillance for dengue and dengue hemorrhagic fever. In: Gubler DJ, Kuno G, editors. Dengue and Dengue Hemorrhagic Fever. Oxford: CAB International; 1997: 405-424.

48. World Health Organization. Global Strategy for Dengue Prevention and Control 2012-2020. Geneva: World Health Organization; 2012. Available from: http://apps.who.int/iris/ bitstream/10665/75303/1/9789241504034_eng.pdf. Accessed August 29, 2014.

49. Department of health and research, New Delhi 12th plan document Available from: http://icmr.nic.in/Publications/plan/ICMR\%20 XIIth\%20Plan\%20(2012-2017).pdf. Accessed November 12, 2014.

50. Thisyakorn U, Thisyakorn C. Latest developments and future directions in dengue vaccines. Ther Adv Vaccines. 2014;2(1):3-9.

51. Capeding MR, Tran NH, Hadinegoro SR, et al; the CYD14 Study Group. Clinical efficacy and safety of a novel tetravalent dengue vaccine in healthy children in Asia: a phase 3, randomised, observer-masked, placebo-controlled trial. Lancet. Epub July 10, 2014.
Infection and Drug Resistance

\section{Publish your work in this journal}

Infection and Drug Resistance is an international, peer-reviewed openaccess journal that focuses on the optimal treatment of infection (bacterial, fungal and viral) and the development and institution of preventive strategies to minimize the development and spread of resistance. The journal is specifically concerned with the epidemiology of antibiotic

\section{Dovepress}

resistance and the mechanisms of resistance development and diffusion in both hospitals and the community. The manuscript management system is completely online and includes a very quick and fair peerreview system, which is all easy to use. Visit http://www.dovepress.com/ testimonials.php to read real quotes from published authors. 